ARTICLE

\title{
In situ observation of thermal-driven degradation and safety concerns of lithiated graphite anode
}

\author{
Xiang Liu (1) 1, Liang Yin², Dongsheng Ren ${ }^{3,4}$, Li Wang (1) 3,4, Yang Ren (1) 2, Wenqian Xu², Saul Lapidus ${ }^{2}$, \\ Hewu Wang ${ }^{4}$, Xiangming He $\mathbb{D}^{3,4}$, Zonghai Chen (1) ${ }^{1}$, Gui-Liang Xu (D) ${ }^{1 凶}$, Minggao Ouyang (1) ${ }^{4 凶} \&$ \\ Khalil Amine (D) 1,5,6凶
}

Graphite, a robust host for reversible lithium storage, enabled the first commercially viable lithium-ion batteries. However, the thermal degradation pathway and the safety hazards of lithiated graphite remain elusive. Here, solid-electrolyte interphase (SEI) decomposition, lithium leaching, and gas release of the lithiated graphite anode during heating were examined by in situ synchrotron X-ray techniques and in situ mass spectroscopy. The source of flammable gas such as $\mathrm{H}_{2}$ was identified and quantitively analyzed. Also, the existence of highly reactive residual lithium on the graphite surface was identified at high temperatures. Our results emphasized the critical role of the SEl in anode thermal stability and uncovered the potential safety hazards of the flammable gases and leached lithium. The anode thermal degradation mechanism revealed in the present work will stimulate more efforts in the rational design of anodes to enable safe energy storage.

\footnotetext{
${ }^{1}$ Chemical Sciences and Engineering Division, Argonne National Laboratory, Lemont, IL, USA. ${ }^{2}$ X-ray Science Division, Advanced Photon Source, Argonne National Laboratory, Lemont, IL, USA. ${ }^{3}$ Institute of Nuclear and New Energy Technology, Tsinghua University, Beijing, China. ${ }^{4}$ State Key Laboratory of Automotive Safety and Energy, Tsinghua University, Beijing, China. ${ }^{5}$ Materials Science and Engineering, Stanford University, Stanford, CA, USA. ${ }^{6}$ Institute for Research\& Medical Consultations (IRMC), Imam Abdulrahman Bin Faisal University (IAU), Dammam, Saudi Arabia. ${ }^{\boxplus e m a i l: x u g @ a n l . g o v ; ~ o u y m g @ t s i n g h u a . ~}$ edu.cn; amine@anl.gov
} 
W ith increasing deployment of higher energy density lithium-ion batteries (LIBs) for portable electronic devices and electric vehicles, critical questions surrounding their battery cycle life and safety hinder their large-scale implementation ${ }^{1,2}$. One of the major trade-offs coexisting with increasing battery energy density are concerns about safety ${ }^{3,4}$. To tackle this issue, intensive efforts have focused on the cathode, such as understanding thermal degradation ${ }^{4-6}$ and developing countermeasures $^{7-9}$, whereas, the thermal degradation pathway and mitigation methods regarding the highly reactive lithiated anode remain elusive. As a result, an adequate practice that can inherently ease the battery safety concern is still missing.

Graphite remains the major anode choice for LIBs because of its overall superior performance, such as high capacity $(372 \mathrm{mAh} / \mathrm{g})$, low working potential $\left(\sim 0.1 \mathrm{~V}\right.$ vs. $\left.\mathrm{Li}^{\prime} \mathrm{Li}^{+}\right)$, cost-effectiveness, and long cycle life ${ }^{10,11}$. During the charge/discharge process, $\mathrm{Li}^{+}$ions are inserted/extracted between the graphene planes without significantly disturbing the graphite host structure, thereby achieving reversible (de)intercalations. The success of graphite anodes enabled the first commercially viable LIBs in the early 1990s by outperforming lithium metal anodes in regard to safety and cycling performance, resulting in the nomination for a 2019 Nobel Prize $^{12,13}$. However, many of the phenomena and mechanisms regarding the thermal stability of lithiated graphite remain unclearly understood, such as the stability of lithiated graphite and the solid-electrolyte interphase (SEI), as well as gas release by the anode under thermal-driven forces, etc ${ }^{14-16}$.

The thermal stability of lithiated graphite, such as $\mathrm{LiC}_{18}, \mathrm{LiC}_{12}$, and $\mathrm{LiC}_{6}$, are barely understood and even remain controversial ${ }^{17-19}$. For example, lithiated graphite was blamed for reacting with oxygen released by the cathode ${ }^{20}$ and even the nonflammable electrolyte ${ }^{21}$, thus triggering catastrophic battery runaway failures. However, direct evidence from in situ observations of those reactions and the underlying mechanisms remains lacking. In addition, by means of the density functional theory (DFT) approach Pande et al. calculated that formation of $\mathrm{LiC}_{6}$ is thermodynamically stable and not affect much with $76 \mathrm{~K}$ temperature increasing 22 . Moreover, experimental characterizations by means of differential scanning calorimetry $(\mathrm{DSC})^{23}$ and X-ray diffraction (XRD) $)^{17}$, earlier work of Drue ${ }^{17}$ and Avdeev et al. ${ }^{23}$ also suggested that the $\mathrm{LiC}_{6}$ is thermodynamically stable up to $250-330^{\circ} \mathrm{C}$. Recent work by Andersson ${ }^{24}, \mathrm{Dahn}^{25}$, and Aurbach et al. ${ }^{19}$ showed, however, that $\mathrm{LiC}_{6}$ starts to decompose at $\sim 80^{\circ} \mathrm{C}$. Such a striking disparity between those results calls for an urgent revisit, especially in an in situ manner to catch any metastable states that would adequately explain the failure modes ${ }^{26}$.

On the SEI side, Winter described the SEI as "the most important and the least understood solid electrolyte in rechargeable Li batteries" 27 , the SEI thermal evolution is also barely known ${ }^{15,28}$. However, the idea that SEI decomposition accounts for the onset of battery self-heating is well accepted ${ }^{3}$. Due to the lack of in situ characterization tools, its evolution under thermal degradation has never been directly monitored.

Last but not the least, swelling and gas species are prevalent in LIBs ${ }^{29,30}$. Among them, flammable gas, such as hydrogen $\left(\mathrm{H}_{2}\right)$, has been extensively observed ${ }^{30-32}$. Nevertheless, the source of the $\mathrm{H}_{2}$ is yet to be determined. It was initially suggested that water impurity may be the source of $\mathrm{H}_{2}\left(\right.$ ref. $\left.{ }^{33}\right)$. At the anode side, $\mathrm{H}_{2} \mathrm{O}$ can be reduced to hydroxide and $\mathrm{H}_{2}$ according to $\mathrm{H}_{2} \mathrm{O}+\mathrm{e}^{-}$ $\rightarrow \mathrm{OH}^{-}+1 / 2 \mathrm{H}_{2}$. However, by quantitative analysis, Wu et al. found that residual moisture is not enough to produce the detected $\mathrm{H}_{2}$, because rather $\sim 2100$ p.p.m. $\mathrm{H}_{2} \mathrm{O}$ is needed ${ }^{34}$. Then Gasteiger et al. suspected that an electrolyte oxidation species, such as the $\mathrm{R}-\mathrm{H}^{+}$, might be the source of $\mathrm{H}_{2}$ (ref. ${ }^{16}$ ). Conversely, by isotope-labeling, Hashimoto et al. proved that the $\mathrm{H}_{2}$ is not derived from the electrolyte, but rather that $\mathrm{H}$ impurities come from the cathode ${ }^{35}$. Nevertheless, recently Cui et al. reported $\mathrm{H}_{2}$ evolution from the graphite anode with lithium dendrite formation, suggesting the $\mathrm{H}_{2}$ may come from the PVDF/SBR binder ${ }^{36,37}$. Furthermore, the $\mathrm{H}_{2}$ gas generation is even more critical under abusive conditions, such as battery thermal failure. Baird et al. summarized the gas composition analysis from the literature over two decades and found that $\mathrm{H}_{2}$ can account for up to $40 \%$ of battery vent gases ${ }^{32}$. However, their source is unclear. Therefore, a comprehensive understanding of gas incubation and evolution is needed.

To provide more insights into the aforementioned issues, we in this work carried out in situ synchrotron high-energy XRD characterization coupled with mass spectroscopy (MS) at the Advanced Photon Source during heating of a lithiated graphite anode, see the in situ experimental scheme in Fig. 1a. (Supplementary Fig. 1 for a lithiated anode sample preparation and Supplementary Fig. 2 for a detailed experimental description). The phase evolution in the lithiated graphite during heating could be traced by distinct XRD reflections, as indicated by time-resolved high-energy XRD data (Supplementary Fig. 3). Meanwhile, the gas evolution due to SEI decomposition and consequential reactions could be tracked in situ and quantitatively analyzed by MS (Supplementary Fig. 2c). Our results showed that, during heating from room temperature to $280^{\circ} \mathrm{C}$, the polyethylene oxide (PEO) oligomer in the SEI decomposed first, starting between 40 and $60^{\circ} \mathrm{C}$, then a typical deintercalation staging effect of graphite was identified through heating, originating from the leaching of lithium. The generated gas species (such as $\mathrm{H}_{2}, \mathrm{CH}_{4}, \mathrm{CO}_{2}, \mathrm{CO}$, and $\mathrm{O}_{2}$, etc.) were quantitively monitored during the whole process. DSC characterization with oxygen exposure experiment further proved the existence of highly reactive residual lithium, which triggered significant heat generation. In situ pair distribution function (PDF) analysis provided convincing evidence that the residual lithium on the anode surface is within a nano-cluster. Our work depicts SEI decomposition, lithium leaching, and gas evolution of the lithiated anode through the thermal degradation, clarifying the essential role of the SEI on the stability of lithiated graphite, and revealing the potential safety hazards posed by the flammable gas and residual liquid lithium.

\section{Results}

With the experiment setup in Fig. 1a and Supplementary Fig. 2, the obtained phase evolution of the lithiated graphite anode during heating is shown in Fig. 1b (contour plots in Supplementary Fig. 4). During heating, the $d$-spacing evolution revealed the phase transformation pattern of $\mathrm{LiC}_{6} \rightarrow \mathrm{LiC}_{12} \rightarrow \mathrm{LiC}_{18} \rightarrow$ graphite, exhibiting a typical staging effect of graphite (see the simulated standard reflections of $\mathrm{LiC}_{6}, \mathrm{LiC}_{12}, \mathrm{LiC}_{18}$, and graphite in Supplementary Fig. 3). This process is very similar to the deintercalation of lithiated graphite ${ }^{38}$, indicating that lithium is gradually removed from the graphite anode lattice through heating. Although a similar lithium deintercalation phenomenon on the lithiated graphite anode was recently observed by Oka et al. $^{26}$, the critical SEI decomposition process elucidated below was significantly missing. In addition, to exclude the possibility of reactions between pure graphite, the PVDF binder, and conductive additives, the in situ high-energy X-ray diffraction (HEXRD) analyses of the heated unlithiated graphite anode with the same content of PVDF binder and conductive additives (carbon black) (95:2:3) were performed. As shown in Supplementary Fig. 5, without lithium intercalation, the graphite showed no phase transformation even when heated to $280^{\circ} \mathrm{C}$. The results confirmed that the unlithiated graphite is stable against PVDF and the carbon additive even at elevated temperature, while the intercalated lithium is the reason for the instability of the lithiated graphite anode. 

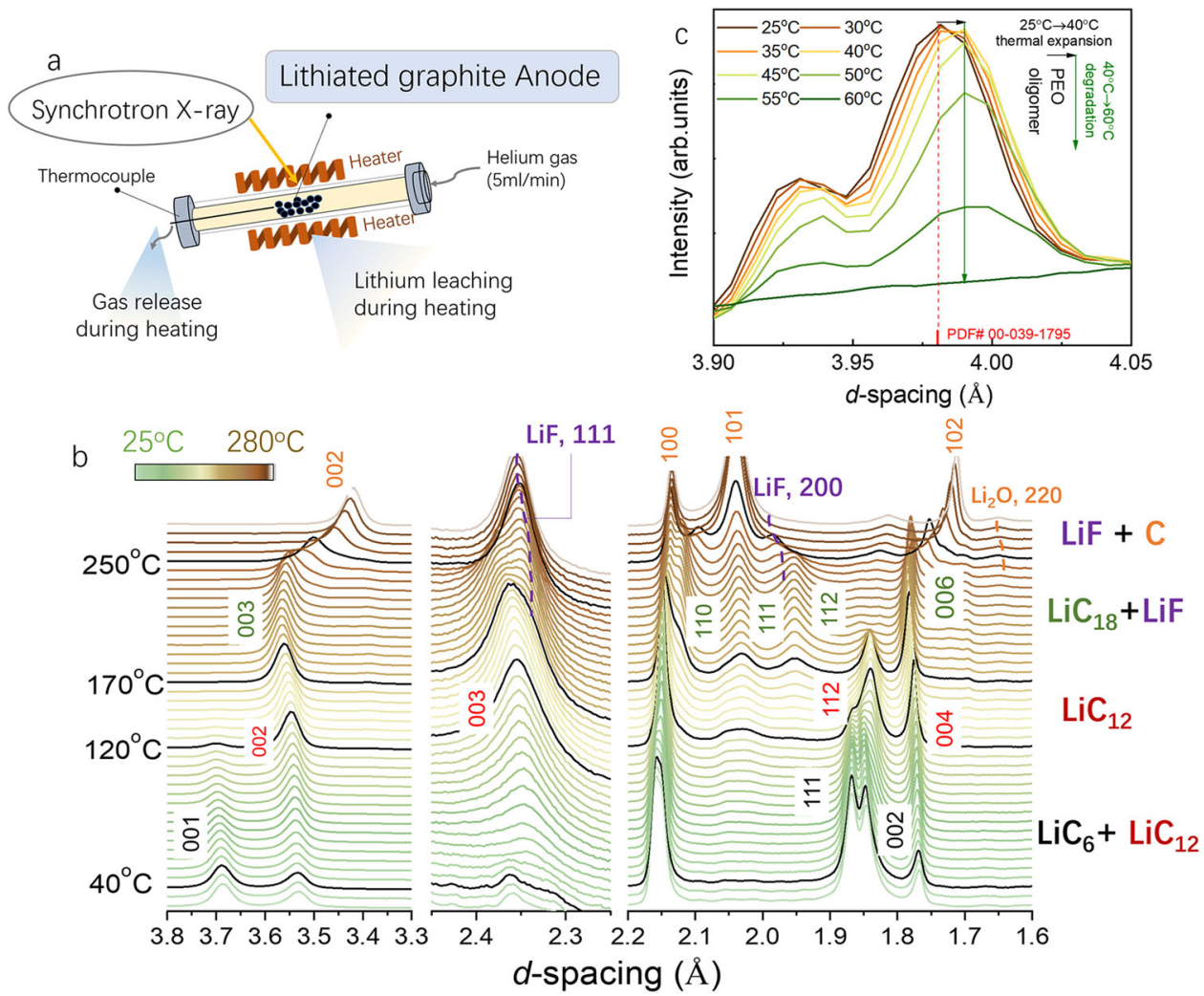

Fig. 1 The structural evolution of lithiated graphite during the heating process. a The scheme of the in situ experimental setup. $\mathbf{b}$ The waterfall plots of lithiated graphite anode during heating from 25 to $280^{\circ} \mathrm{C}$ with $2{ }^{\circ} \mathrm{C} / \mathrm{min}$. The $2 \theta$ value has been converted into $d$-spacing following Bragg's rule for a better comparison to the results using different $\mathrm{X}$-ray sources. c The polyethylene oxide (PEO) oligomer lattice expansion between 25 and $40{ }^{\circ} \mathrm{C}$, with a coefficient of thermal expansion (CTE) of $167 \times 10^{-6}{ }^{\circ} \mathrm{C}$, then PEO degradation during $40-60^{\circ} \mathrm{C}$.

It is widely accepted that during the initial heating the metastable part of the SEI will decompose first ${ }^{1,3}$. Given the importance of the SEI on battery performance, there have been numerous studies aiming to understand the chemical composition and properties of the $\mathrm{SEI}^{39-43}$. However, challenges still exist due to its complexity and sensitive nature, especially with regard to its thermal stability. As a result, only a few reports proposed the thermal impact on the $\mathrm{SEI}^{44-46}$, and were mostly based on ex situ characterizations. Here, by using advanced synchrotron XRD for high phase sensitivity, we for the first time directly observed the thermal expansion and breakdown of the PEO oligomer. PEO oligomer $\left(-\mathrm{CH}_{2}-\mathrm{CH}_{2}-\mathrm{O}\right)_{n}$ was reported as one of the major ingredients of the outer part of the SEI by $\mathrm{XPS}^{47,48}, \mathrm{NMR}^{49}, \mathrm{FTIR}^{50}$, and DFT calculation ${ }^{51}$, usually derived from ethene carbonate (EC) and ethyl methyl carbonate decomposition during the charging process of LIBs. As shown in Fig. 1c, from the initial heating starting at $25-40^{\circ} \mathrm{C}$, the PEO XRD reflection sensitively right shifted, indicating a lattice expansion (see also Supplementary Fig. 6a). The thermal expansion co-efficiency derived from the reflection at $3.98 \AA$ is $167 \times 10^{-6}{ }^{\circ} \mathrm{C}$, which is well consistent with the range for polymer materials $\left(20-200 \times 10^{-6}{ }^{\circ} \mathrm{C}\right)$, while much larger than that for inorganics, such as graphite $\left(8 \times 10^{-6}{ }^{\circ} \mathrm{C}\right)^{52}$. Meanwhile, at this stage, the reflection intensities of $\mathrm{LiC}_{6}(001)$ and $\mathrm{LiC}_{12}$ (002) stay constant (see Supplementary Fig. 7 for Bragg reflection fitting results and Supplementary Fig. 8 for the original plots, confirming no lithium leaching at this stage). With a further temperature increase $>40^{\circ} \mathrm{C}$, the $\mathrm{PEO}$ reflection faded and completely vanished at $60^{\circ} \mathrm{C}$, implying the breakdown of this SEI component, as shown in Fig. 1c and Supplementary Fig. 6b. Concurrently, starting at $40^{\circ} \mathrm{C}$, the $\mathrm{LiC}_{6}$ Bragg reflection began to decrease with the $\mathrm{LiC}_{12}$ increasing, corresponding to the lithium leaching out process.
With further heating, the lithium continued the deintercalation until at $\sim 120^{\circ} \mathrm{C}$, when the $\mathrm{LiC}_{6}$ phase faded; then, at $\sim 170^{\circ} \mathrm{C}$, the $\mathrm{LiC}_{12}$ phase vanished; finally, starting at $\sim 250^{\circ} \mathrm{C}$, the $\mathrm{LiC}_{18}$ phase also disappeared with the onset of the graphite $2 \mathrm{H}$ phase, shown in Fig. $1 b$.

Furthermore, the Rietveld refinement of the HEXRD patterns were performed to quantitively reveal the phase ratio of the graphite anode before and after being heated to $280^{\circ} \mathrm{C}$. As shown in Fig. 2a, the ratio of $\mathrm{LiC}_{6}$ and $\mathrm{LiC}_{12}$ in the lithiated graphite anode before heating is 49.2:50.8, indicating a designed N:P ratio (negative capacity to positive capacity ratio) of a commercial lithium-ion cell to prevent lithium dendrites, typically $~ 1.1: 1$. However, after been heated to $280^{\circ} \mathrm{C}$, the $\mathrm{Li}_{2} \mathrm{O}$ (30.4 wt.\%) and LiF (5.1 wt.\%) phases also exist in addition to the majority of graphite $2 \mathrm{H}$ phase (64.6 wt.\%); see Fig. $2 \mathrm{~b}$, indicating that the extracted lithium was converted to $\mathrm{Li}_{2} \mathrm{O}$ and $\mathrm{LiF}$ during heating. The enlarged Bragg reflection plots focused on tracing the $\mathrm{LiF}$ $(111,200)$ and $\mathrm{Li}_{2} \mathrm{O}(111,220)$ reflections during heating are shown in Fig. 2c, d, respectively. As shown, the formation of $\mathrm{LiF}$ and $\mathrm{Li}_{2} \mathrm{O}$ started at $\sim 170$ and $180^{\circ} \mathrm{C}$, respectively.

The reaction between the lithiated anode and PVDF/SBR binders, which accounts for a major heat generation reaction on the anode side, is usually reported by calorimetry characterizations, such as DSC and accelerated rate calorimeter (ARC) $)^{18,53,54}$. However, more than one exothermic reaction exists at high temperature $\left(>150{ }^{\circ} \mathrm{C}\right)^{53}$. Therefore, only monitoring the heat is not convincing enough to ascertain the reaction. Here, for the first time, we certified this reaction by tracing the reaction products, which are $\mathrm{LiF}$ and $\mathrm{H}_{2}$ gas. Starting at $\sim 170^{\circ} \mathrm{C}$, the leached lithium can react with PVDF binder and lead to the formation of 

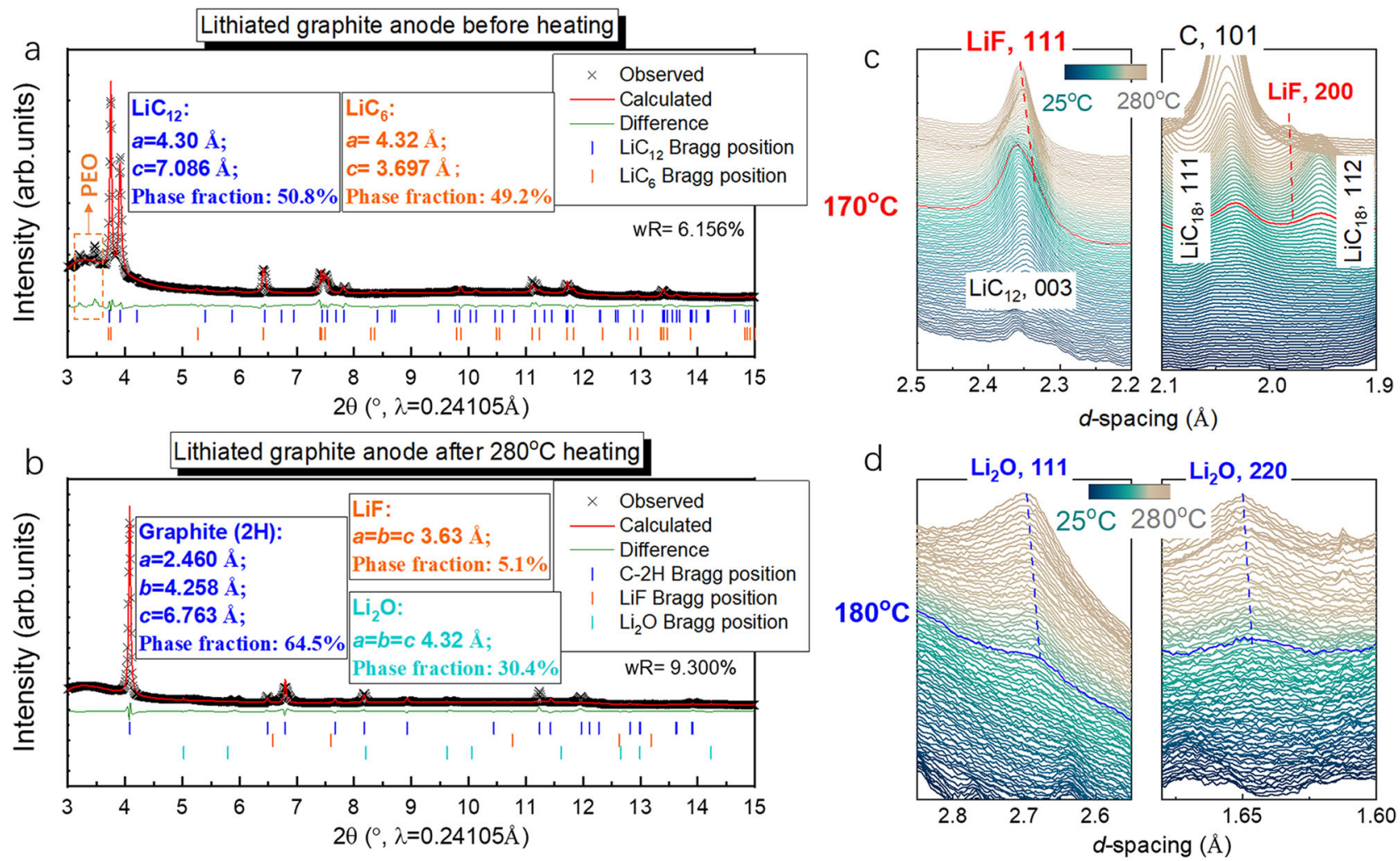

Fig. 2 The $\mathbf{L i F}$ and $\mathbf{L i}_{2} \mathbf{O}$ formation during the heating process. a The Rietveld refinement of lithiated anode before heating. $\mathbf{b}$ The Rietveld refinement of lithiated anode after heating to $280^{\circ} \mathrm{C}$. c The formation of LiF by tracing the LiF (111) and (200) Bragg reflections. $\mathbf{d ~} \mathrm{Li}_{2} \mathrm{O}$ formation by tracing the $\mathrm{Li} 2 \mathrm{O}$ (111) and (220) Bragg reflections.

$\mathrm{LiF}$ and $\mathrm{H}_{2}$, as shown in reaction (1):

$$
\begin{aligned}
& \mathrm{Li}+\left(-\mathrm{CF}_{2}-\mathrm{CH}_{2}-\right)_{2} \rightarrow \mathrm{H}_{2}(\mathrm{~g})+\mathrm{LiF} \\
& \quad+(-\mathrm{CH}=\mathrm{CH}-\mathrm{CH}=\mathrm{CH}-)\left(\sim 170^{\circ} \mathrm{C}\right)\left(\text { refs. }{ }^{18,36,53,54}\right)
\end{aligned}
$$

Tracing the gas evolution can significantly enhance our understanding of the battery chemistry, for example, the SEI formation and cathode degradation $4,5,29,55,56$. This is increasingly important in battery failure analysis, because of the release of flammable and toxic gases at high temperatures, such as $\mathrm{H}_{2}, \mathrm{CH}_{4}$, and $\mathrm{C}_{2} \mathrm{H}_{4}$, incontrovertibly raises the explosive hazard ${ }^{30,57,58}$.

Here, multiple gas species $\mathrm{H}_{2}(m / z=2), \mathrm{CH}_{3}{ }^{\bullet}(m / z=15), \mathrm{CH}_{4}$ $(m / z=16), \mathrm{C}_{2} \mathrm{H}_{4} / \mathrm{CO}(m / z=28), \mathrm{O}_{2}(m / z=32), \mathrm{CO}_{2}(m / z=$ 44), $\mathrm{C}(\mathrm{m} / z=12), \mathrm{CH}^{\bullet}(\mathrm{m} / z=13)$, and $\mathrm{NO}_{2}(\mathrm{~m} / z=46)$ were traced and quantitatively analyzed during the heating process of a lithiated graphite anode, as shown in Fig. 3a-f and Supplementary Figs. 9-11. All the generated gas intensity is normalized according to the intensity of the helium $(m / z=4)$ flow gas set at $5 \mathrm{~mL} / \mathrm{min}$. The $\mathrm{H}_{2}, \mathrm{CH}_{4}, \mathrm{CO} / \mathrm{C}_{2} \mathrm{H}_{4}$, and $\mathrm{CO}_{2}$ gases were four major gas species during the initial heating process from room temperature to $170{ }^{\circ} \mathrm{C}$. Although the main signal of $\mathrm{CO}$ at $\mathrm{m} / \mathrm{z}=$ 28 is overlapped signal from $\mathrm{C}_{2} \mathrm{H}_{4}$, they can be distinguished by means of specific fragmentation patterns, as CO has a fragmentation pattern of carbon at $m / z=12$ (Supplementary Fig. 9), while $\mathrm{C}_{2} \mathrm{H}_{4}$ usually does not ${ }^{59}$. We can then assign the first peak of $m / z=28$ to $\mathrm{CO}$ and the second peak starting after $170{ }^{\circ} \mathrm{C}$ to $\mathrm{C}_{2} \mathrm{H}_{4}$, since there is no $\mathrm{C}$ fragment during this stage.

Enlarged gas signals focusing between 40 and $80^{\circ} \mathrm{C}$ are shown in Supplementary Fig. 12, in which the $\mathrm{CH}_{4}, \mathrm{CO} / \mathrm{C}_{2} \mathrm{H}_{4}$, and $\mathrm{CO}_{2}$ channels have shown a sharp increase between 45 and $65^{\circ} \mathrm{C}$, corresponding to the SEI decomposition between 40 and $\sim 60^{\circ} \mathrm{C}$ as observed by HEXRD. Due to the tubing used for gas transition, the gas signal shows a slight delay $\left(5^{\circ} \mathrm{C}\right)$. The PEO oligomer
$\left(-\mathrm{CH}_{2}-\mathrm{CH}_{2}-\mathrm{O}-\right)_{n}$ degrades predominantly by random chain scission of the backbone with the elimination of smaller fragments, such as $\mathrm{CO} / \mathrm{C}_{2} \mathrm{H}_{4}, \mathrm{CH}_{4}$, and $\mathrm{CO}_{2}$ (reaction (2) $)^{60,61}$. The decompositions of other SEI components also possibly lead to releases of $m / z=16,28$, and 44 gases, such as lithium ethylene dicarbonate (LEDC), $\mathrm{Li}_{2} \mathrm{CO}_{3}, \mathrm{ROCO}_{2} \mathrm{Li}, \mathrm{ROLi}\left(\mathrm{R}=\mathrm{CH}_{3}-\right.$, $\mathrm{CH}_{3}-\mathrm{CH}_{2}-, \mathrm{CH}_{3}-\mathrm{CH}_{2}-\mathrm{CH}_{2}-$, etc.), following the below reactions (reactions $(3-5))^{15,55,62,63}$ :

$$
\begin{gathered}
\left(-\mathrm{CH}_{2}-\mathrm{CH}_{2}-\mathrm{O}-\right)_{n} \rightarrow \mathrm{H}_{2}(\mathrm{~g})+\mathrm{CH}_{x}+\mathrm{CO}(\mathrm{g}) \\
+\mathrm{H}_{2} \mathrm{O}+\left(-\mathrm{CH}_{2}-\mathrm{O}-\right)_{n-2}\left(\text { refs. }{ }^{60,61}\right) \\
\mathrm{LEDC} \rightarrow \mathrm{Li}_{2} \mathrm{CO}_{3}+\mathrm{C}_{2} \mathrm{H}_{4}(\mathrm{~g})+\mathrm{CO}(\mathrm{g})+\mathrm{CH}_{3} \mathrm{CH}_{2} \mathrm{CO}_{2} \mathrm{Li}\left(\text { refs. }{ }^{15,55,62}\right)
\end{gathered}
$$

$\mathrm{ROCO}_{2} \mathrm{Li}+\mathrm{H}_{2} \mathrm{O} \rightarrow \mathrm{Li}_{2} \mathrm{CO}_{3}+\mathrm{CO}_{2}(\mathrm{~g})+\mathrm{LiOR}$ (refs. ${ }^{15,55,62,63}$ )

$$
\left(\mathrm{CH}_{2} \mathrm{OCO}_{2} \mathrm{Li}\right)_{2} \rightarrow \mathrm{Li}_{2} \mathrm{CO}_{3}+\mathrm{C}_{2} \mathrm{H}_{4}(\mathrm{~g})+\mathrm{CO}_{2}(\mathrm{~g})+\mathrm{O}_{2}(\mathrm{~g})\left(\text { refs. }{ }^{55,63}\right)
$$

At $\sim 100{ }^{\circ} \mathrm{C}$, the maximum gas release rate of the $\mathrm{CH}_{4}, \mathrm{CO} /$ $\mathrm{C}_{2} \mathrm{H}_{4}, \mathrm{O}_{2}$, and $\mathrm{CO}_{2}$ was $0.06,0.09,0.02$, and $0.25 \mu \mathrm{L} / \mathrm{min} / \mathrm{mg}$, respectively, with a cumulative ratio of $7.3 \%\left(\mathrm{CH}_{4}\right), 21.2 \%(\mathrm{CO} /$ $\left.\mathrm{C}_{2} \mathrm{H}_{4}\right), 10.1 \%\left(\mathrm{O}_{2}\right)$, and $22.0 \%\left(\mathrm{CO}_{2}\right)$; see Fig. $3 \mathrm{~g}$ and Supplementary Fig. 13. The ratio between $\mathrm{CO} / \mathrm{CO}_{2}$ and $\mathrm{CH}_{4}$ indicated that the decomposition of lithium alkyl carbonates (following reactions (3-5)) is the main gas release reaction, compared with $\mathrm{PEO}$ oligomer degradation (with $\mathrm{CH}_{4}$ production, reaction (2)).

As for the $\mathrm{H}_{2}$ gas, see Supplementary Fig. 12, the $\mathrm{H}_{2}$ intensity increased exponentially as the temperature increased from 40 to $80^{\circ} \mathrm{C}$, in contrast with the appearance of a plateau at $\sim 70^{\circ} \mathrm{C}$ in 

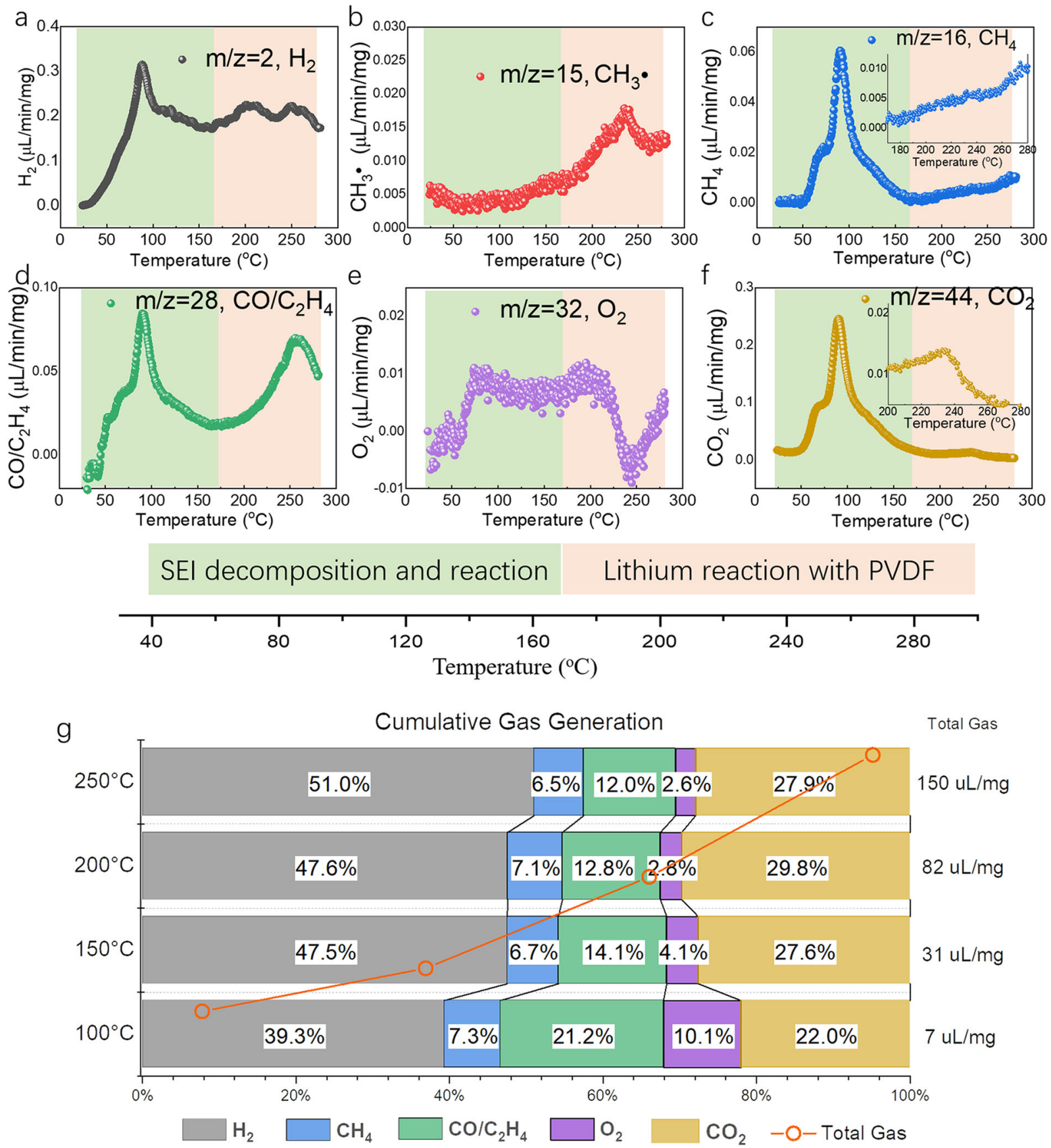

Fig. 3 The in situ gas release of lithiated graphite anode during heating. a-f The in situ monitoring of $\mathrm{H}_{2}, \mathrm{CH}_{3}, \mathrm{CH}_{4}, \mathrm{CO} / \mathrm{C}_{2} \mathrm{H}_{4}, \mathrm{O}_{2}$, and $\mathrm{CO}_{2}$ gas evolution during the heating of the lithiated graphite anode. $\mathbf{g}$ The quantitative analysis of the cumulative gas ratio at $100,150,200$, and $250{ }^{\circ} \mathrm{C}$.

other SEI degradation-derived gas evolution curves $\left(\mathrm{CH}_{4}, \mathrm{CO} /\right.$ $\mathrm{C}_{2} \mathrm{H}_{4}$, and $\mathrm{CO}_{2}$ ), indicating the $\mathrm{H}_{2}$ was related to the leached lithium rather than the SEI decomposition. This is because the leached lithium linearly increased as revealed by HEXRD, compared to the breakdown and then disappearance of SEI. The leached lithium may also react with residual $\mathrm{H}_{2} \mathrm{O}$ or $\mathrm{ROH}$ for $\mathrm{H}_{2}$ gas release ${ }^{16,64-66}$ :

$$
\begin{gathered}
2 \mathrm{ROH}+\mathrm{Li} \rightarrow \mathrm{H}_{2}(\mathrm{~g})+2 \mathrm{ROLi}\left(\text { refs. }^{16,64}\right) \\
\mathrm{Li}+\mathrm{H}_{2} \mathrm{O} \rightarrow \mathrm{H}_{2}(\mathrm{~g})+\mathrm{LiOH}\left(\text { ref. }{ }^{16}\right) \\
\mathrm{Li}+\mathrm{O}_{2} \rightarrow \mathrm{Li}_{2} \mathrm{O}\left(\text { ref. }^{65}\right)
\end{gathered}
$$

The gas release intensity of $\mathrm{CO} / \mathrm{C}_{2} \mathrm{H}_{4}, \mathrm{CH}_{4}$, and $\mathrm{CO}_{2}$ rapidly decreased after the majority of SEI decomposed at $100^{\circ} \mathrm{C}$; see Fig. $3 c$, d, f. However, the $\mathrm{H}_{2}$ remains at a relatively high level of $\sim 0.2 \mu \mathrm{L} / \mathrm{min} / \mathrm{mg}$, confirming the continuous drain out of lithium from the graphite. After $170^{\circ} \mathrm{C}$, the reaction between leached $\mathrm{Li}$ and PVDF binder (reaction (1)) activated. Thus, the $\mathrm{H}_{2}$ intensity increased again; see Fig. 3a. Meanwhile, the gas of $\mathrm{CH}_{3}(\mathrm{~m} / z=$ 15) fragment, $\mathrm{CH}_{4}(\mathrm{~m} / \mathrm{z}=16)$, and $\mathrm{C}_{2} \mathrm{H}_{4}(\mathrm{~m} / \mathrm{z}=28)$ were also increasingly detected as a result of the PVDF $\left(-\mathrm{CF}_{2}-\mathrm{CH}_{2}-\right)_{n}$ decomposition reaction to eliminate the small hydrocarbon fragments. To sum up, with in situ mass spectrometry, the gas release of the lithiated anode was quantitively analyzed through heating. The $\mathrm{H}_{2}, \mathrm{CO} / \mathrm{C}_{2} \mathrm{H}_{4}, \mathrm{CH}_{4}$, and $\mathrm{CO}_{2}$ were the main gas products initially during the SEI decomposition and the 
associated reaction, and after $170{ }^{\circ} \mathrm{C}$, the leached lithium reacted with PVDF and other residual oxygen-containing ingredients, with the production of $\mathrm{LiF}, \mathrm{H}_{2}$ gas, and $\mathrm{Li}_{2} \mathrm{O}$. These two processes are indicated with light green and orange color in Fig. 3a-f. Consequently, the cumulative gas produced from the lithiated anode at $250{ }^{\circ} \mathrm{C}$ (a typical thermal runaway temperature of commercial $\mathrm{LIBs}^{67}$ ) is $\sim 150 \mu \mathrm{L} / \mathrm{mg}_{\text {anode }}$ with the ratios of $51 \%$ $\left(\mathrm{H}_{2}\right), 6.5 \%\left(\mathrm{CH}_{4}\right), 12.0 \%\left(\mathrm{CO} / \mathrm{C}_{2} \mathrm{H}_{4}\right), 2.6 \%\left(\mathrm{O}_{2}\right)$, and $27.9 \%$ $\left(\mathrm{CO}_{2}\right)$. The total gas volume measured here $\left(150 \mu \mathrm{L} / \mathrm{mg}_{\text {anode }}\right)$ is comparable to the report of the vented gas analysis of largeformat LIBs by Yuan et al. with $36.5-245 \mu \mathrm{L} / \mathrm{mg}_{\text {battery }}{ }^{68}$, considering the fluctuation caused by gas generation from the electrolyte and cathode in commercial full LIBs. On the other hand, compared to the vented gas composition of full $\mathrm{LIBs}^{30-32}$, the anode-released gas showed a higher $\mathrm{H}_{2}$ concentration, suggesting that the $\mathrm{H}_{2}$ gas is mainly driven from the anode rather than the cathode or electrolyte. Oppositely, the $\mathrm{CO}_{2}$ ratio is lower than that in the full batteries, indicating the generation of $\mathrm{CO}_{2}$ in the full cells comes from the decomposition of cathode and electrolytes. By the advantages of time-resolved measurement, we revealed that the one major SEI component-PEO oligomer, accounts for the initial $\mathrm{H}_{2}$ gas release, by reaction (2); while the other SEI component-lithium alkyl carbonate $\left(\mathrm{ROCO}_{2} \mathrm{Li}\right)$ accounts for the $\mathrm{CO}_{2}$ generation, following reaction (4).

Post-analysis was conducted to further confirm the degradation pathways of the lithiated graphite; see details in the Supplementary Information. Before charging, as shown in Fig. 4a, it is observed that the mesoporous graphite anode with a particle size $\sim 15 \mu \mathrm{m}$, and the PVDF binder and conductive carbon black are on the surface and gaps of graphite. During heating, the drainedout lithium from the graphite lattice can gather around at the edges of graphite flakes (moving out along the in-plane direction), as illustrated in Fig. 4b. The accumulated lithium can react first with the SEI components. Then, with a further temperature increase, the lithium reaction with the PVDF binder happened with $\mathrm{LiF}$ formation and $\mathrm{H}_{2}$ gas release. Therefore, as shown in Fig. 4c, a thick layer of reaction products was observed after reaching $280^{\circ} \mathrm{C}$ (anode collected after natural cooling), covering the anode surface. Moreover, the vigorous reaction of drained lithium can cause the exfoliation of the graphite layer. In the cases of a full battery with a liquid electrolyte or a cathode oxygen gas release, such exfoliation of graphite may exponentially increase the reaction area and expose more lithium through the opened graphene layer, thus leading to the rapid heat generation.

Note that, due to the limited amount of PVDF binder (anode composition $95 \mathrm{wt} . \%$ graphite, $2 \mathrm{wt} . \%$ PVDF, and $3 \mathrm{wt} . \%$ carbon black), only $5.2 \mathrm{wt}$ \% of the total leached lithium is consumed by reaction (1); with another $55.5 \mathrm{wt} . \%$ of leached lithium consumed by the SEI layer, see Supplementary Notes 1 and 2, and Supplementary Table 1 . Thus, 39.3 wt.\% of the residual liquid lithium can exist on the graphite surface at high temperatures, leading to great potential hazards. To confirm this hypothesis, an oxygen exposure experiment was designed during the DSC measurements to simulate the thermal-induced oxygen release from the layered cathode ${ }^{5,20}$ and/or the solid-state electrolyte ${ }^{65}$ in a full battery; see Fig. 4d. The DSC purge gas was swift from inert nitrogen to oxygen at the designated high temperatures, such as 200,240 , and $260^{\circ} \mathrm{C}$. As shown, with oxygen exposure, an immediate heat generation peak was triggered, with 123,795 , and $852 \mathrm{~J} / \mathrm{g}$ at 200,240 , and $260^{\circ} \mathrm{C}$, respectively. As indicated by HEXRD, the phase composition at 200,240 , and $260^{\circ} \mathrm{C}$ can be identified to calculate the weight ratio of leached lithium; see Supplementary Table 1 . At $200^{\circ} \mathrm{C}$, almost all the leached lithium (3.72 wt.\%, based on the total weight of lithiated graphite) reacted with the SEI, leaving limited amount of residual leached lithium, as indicated by the heat generation of only $123 \mathrm{~J} / \mathrm{g}$. However, from 200 to $240{ }^{\circ} \mathrm{C}, 2.1 \mathrm{wt} . \%$ more lithium was drained from the graphite anode. Based on the reaction entropy of $4 \mathrm{Li}+\mathrm{O}_{2} \rightarrow$ $2 \mathrm{Li}_{2} \mathrm{O} \quad\left(\Delta H=-299.4 \mathrm{~kJ} / \mathrm{mol}_{\text {lithium }}\right)^{65}$, theoretically, at most $905.96 \mathrm{~J} / \mathrm{g}(2.1 \% \times 299.4 / 6.94 \mathrm{~kJ} / \mathrm{g})$ heat would be generated (see Supplementary Note 2). This is within the same order of magnitude as our experimental observation of $795 \mathrm{~J} / \mathrm{g}$, indicating good consistency in battery heat generation ${ }^{54}$. With the temperature further increased to $260{ }^{\circ} \mathrm{C}$, the theoretical heat generation with 2.98 wt.\% (2.1 + 0.88wt.\%) residual lithium was $1285.6 \mathrm{~J} / \mathrm{g}$, compared to $852 \mathrm{~J} / \mathrm{g}$ with the experimental measurement. Considering that the leached lithium can also be consumed in other reactions, as indicated by gas release and $\mathrm{Li}_{2} \mathrm{O}$ formation at high temperatures, a lower measured heat generation is quite reasonable. Note that only the lithiated graphite anode evolved in this experiment, and at this temperature, the reaction between graphite and oxygen was not activated (graphite $+\mathrm{O}_{2} \rightarrow \mathrm{CO}_{2}$ occurred at $400-1200^{\circ} \mathrm{C}$, ref. ${ }^{69}$ ), which is also indicated by the limited amount of $\mathrm{CO}_{2}$ generation at high temperature (Fig. 3f). The existence of residual lithium is the most possible answer that accounts for this large heat generation. Traditionally, the flammable carbonate electrolyte was considered as a "fuel tank" due to a large energy release with combustion through thermal runaway. Here, for the first time, we revealed that the residual lithium leached out on the graphite anode surface is the true source accounting for this significant energy release during thermal failure.

Furthermore, although the process of lithium draining was confirmed by HEXRD phase evolution $\left(\mathrm{LiC}_{6} \rightarrow \mathrm{LiC}_{12} \rightarrow\right.$ $\mathrm{LiC}_{18} \rightarrow$ graphite) and the residual lithium was indicated by DSC heat generation, there was no direct ordered lithium body-centercubic (bcc) structure identified through the heating by in situ HEXRD, as shown in Supplementary Fig. 14. If the well-ordered bcc stacking of lithium atoms was formed with a long enough coherence length (Fig. $4 \mathrm{e}$ ), the reflection at $5.56^{\circ}$, indexing the most intense scattering of $\mathrm{Li}$ (110) plane, should have been observed ${ }^{70}$. However, there is no such Bragg reflection throughout the heating. To probe the structure of the leached lithium, we further conducted in situ PDF analysis (see experimental details in Supplementary Fig. 15), which is a useful method for analyzing both crystalline and amorphous materials ${ }^{71}$. As shown in Fig. 4f, the calculated PDF patterns of $\mathrm{LiC}_{6}, \mathrm{LiC}_{12}, \mathrm{LiC}_{18}$, and bcc-stacked lithium are also present in the figure for a better peak index. The primary PDF peaks at $1.41,2.45,2.83$, and $3.75 \AA$ are attributed to the well-ordered $\mathrm{C}-\mathrm{C}$ bonding of the in-plane graphene layer ${ }^{72}$ (see Supplementary Fig. 16 for illustration). C-C bonding, especially those with a short range $(1.41,2.45$, and $2.83 \AA$ ), remained unchanged during the heating, indicating a stable in-plane carbon host structure. As for the Li-Li bonding, a shoulder peak at $3.51 \AA$ was identified at high temperatures of 280 and $320^{\circ} \mathrm{C}$. However, compared with the pure liquid lithium PDF revealed by Chen and Salmon et al. ${ }^{73,74}$, the longer-range $\mathrm{Li}-\mathrm{Li}$ peak $(5.82 \AA)$ was not observed in our case. The result may indicate that the leached lithium from graphite was well-distributed and formed nanocluster aggregates, thus exhibiting no long-range order after the first coordination sphere $(3.5 \AA)$. In addition, with nano-cluster lithium, the high surface area greatly boosted its reactivity, leading to more severe safety concerns.

\section{Discussion}

By using in situ synchrotron XRD coupled with MS and X-ray scattering PDF analysis, the unprecedented picture of battery thermal failure on the anode side was comprehensively illustrated here. As shown in Fig. 5a, a stable SEI layer consisting of LEDC, PEO oligomer, $\mathrm{Li}_{2} \mathrm{CO}_{3}, \mathrm{LiF}$, and lithium alkyl carbonates, etc., formed on the graphite anode after the formation process. During 

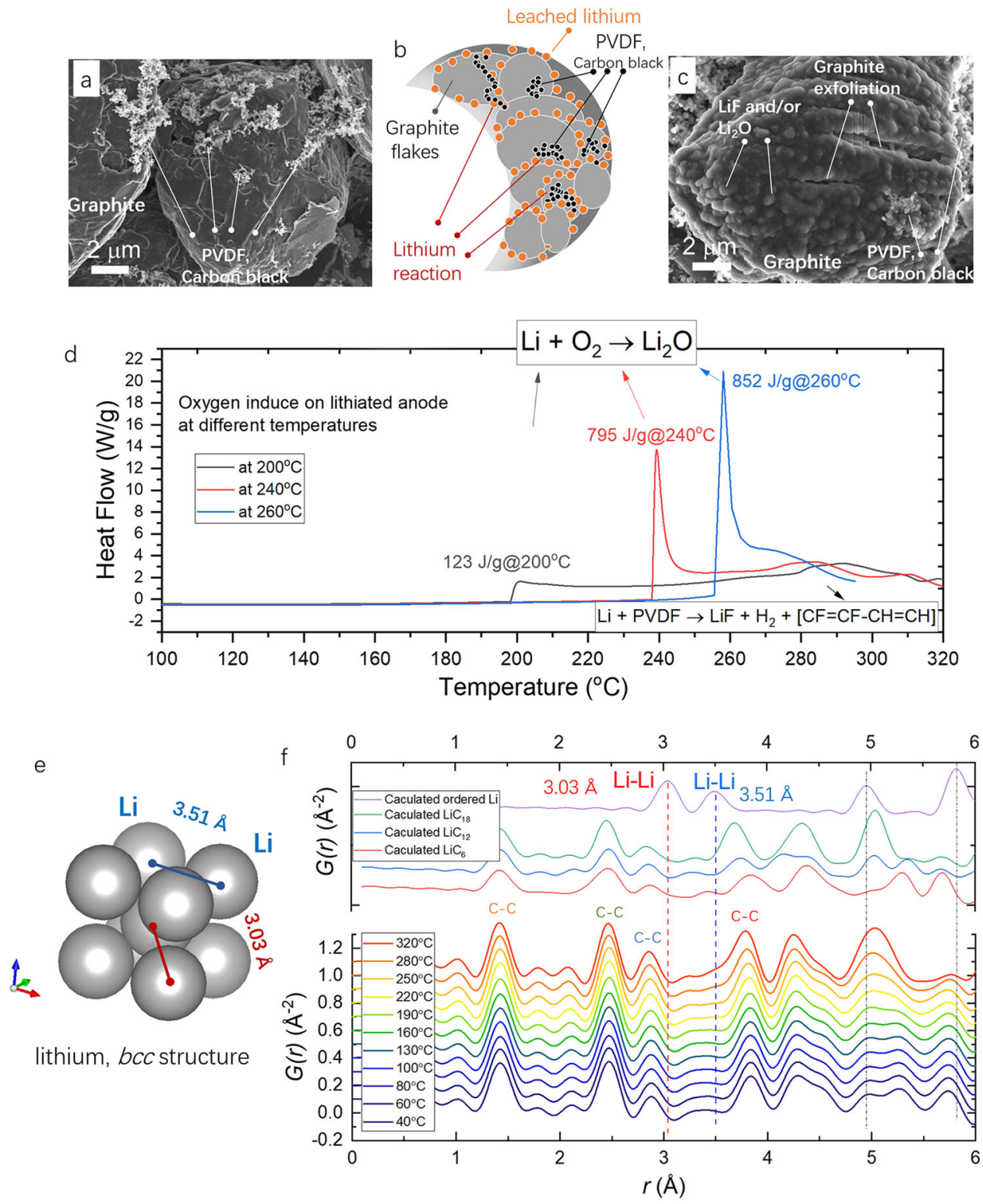

Fig. 4 The post-analysis and in situ PDF of the lithiated graphite anode. a SEM image of the graphite anode before heating. $\mathbf{b}$ An illustration of the lithium leaching and reaction process on the edges of graphite flakes. c SEM image of the lithiated graphite anode after $280^{\circ} \mathrm{C}$ heating. $\mathbf{d}$ The influence of oxygen on lithiated graphite anode at different temperatures during the DSC measurements. e The illustration of lithium bcc atomic structure. $\mathbf{f}$ The in situ PDF analysis of the lithiated graphite anode during the heating.

the initial heating, see Fig. 5b, the PEO oligomer starts to decompose from $40^{\circ} \mathrm{C}$, followed by the degradation of LEDC and $\mathrm{ROCO}_{2} \mathrm{Li}$ until $\sim 100^{\circ} \mathrm{C}$. The lithium begins to leach out after the SEI damage (denoted by the blue arrow) and reacts with the remaining SEI ingredients, thus leading to increased $\mathrm{H}_{2}, \mathrm{O}_{2}, \mathrm{CH}_{4}$, and $\mathrm{CO}_{2}$ gas releases. The cumulative gas is $7 \mu \mathrm{L} / \mathrm{mg}_{\text {anode }}$ with ratios of $39.3 \%\left(\mathrm{H}_{2}\right), 7.3 \%\left(\mathrm{CH}_{4}\right), 21.2 \%\left(\mathrm{CO} / \mathrm{C}_{2} \mathrm{H}_{4}\right), 10.1 \%\left(\mathrm{O}_{2}\right)$, and $22.0 \%\left(\mathrm{CO}_{2}\right)$ at $100^{\circ} \mathrm{C}$. Then starting at $170{ }^{\circ} \mathrm{C}$, the reaction between lithium and PVDF leads to the formation of $\mathrm{LiF}$ and more $\mathrm{H}_{2}$ gas; Fig. $5 c$. Nevertheless, not all the leached lithium is consumed by the SEI and PVDF. With a further temperature increase to $180^{\circ} \mathrm{C}$, the residual lithium starts to melt to further increase its reactivity with a lower density, higher porosity, and tortuosity at the liquid amorphous state ${ }^{71}$. Therefore, $39.3 \mathrm{wt} . \%$ of residual liquid lithium existing on the graphite surface raises a major safety concern, see Fig. 5d, because it is ready to react with cathode/SSE-released oxygen and/or the liquid electrolyte to trigger thermal runaway. In addition, at $250^{\circ} \mathrm{C}$, the large portion of flammable gas also raises a great explosive hazard, as the cumulative gas is $150 \mu \mathrm{L} / \mathrm{mg}_{\text {anode }}$ with $51 \%\left(\mathrm{H}_{2}\right), 6.5 \%\left(\mathrm{CH}_{4}\right)$, and $12.0 \%\left(\mathrm{CO} / \mathrm{C}_{2} \mathrm{H}_{4}\right)$.

In practical LIBs, the electrolyte exists as one important component that affects battery safety. Thus, the in situ HEXRD analysis of the degradation of the lithiated graphite degradation with the presence of electrolyte was conducted further; see the results in Fig. 6 and the contour plots in Supplementary Fig. 17. As shown, with the presence of electrolyte, the lithiated graphite anode follows similar phase transformation pathways as the dry lithiated graphite, exhibiting the typical $\mathrm{LiC}_{6} \rightarrow \mathrm{LiC}_{12} \rightarrow \mathrm{LiC}_{18} \rightarrow$ graphite phase evolution. However, the reaction kinetics were increased significantly. Specifically, the $\mathrm{LiC}_{6}$ (001) reflection started to decrease immediately upon heating (Fig. 6a), compared to $60^{\circ} \mathrm{C}$ in the case of dry lithiated graphite. Moreover, with the presence of electrolyte, the $\mathrm{LiF}$ (110) reflection started to appear at $\sim 114^{\circ} \mathrm{C}$, compared to $170{ }^{\circ} \mathrm{C}$ for the dry lithiated graphite, suggesting the leached lithium reacted with the electrolyte; see 

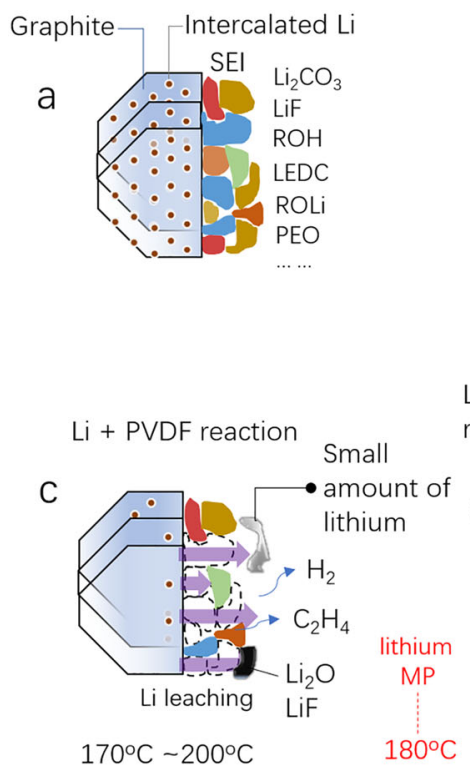

SEl decomposition

b

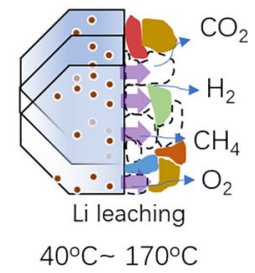

Large amount of residual liquid lithium

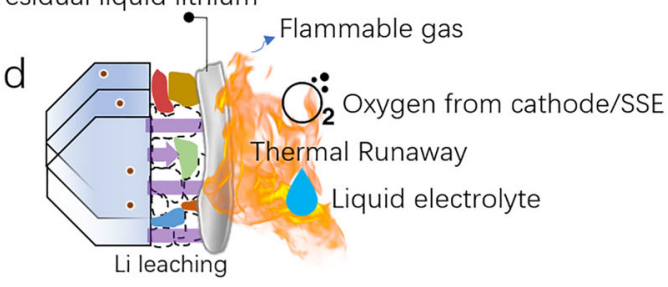

$200^{\circ} \mathrm{C} \sim 280^{\circ} \mathrm{C}$

Fig. 5 The thermal degradation pathway of lithiated graphite anode and its safety hazards. a-c The thermal evolution of the lithiated graphite anode revealed by multiple in situ characterizations. $\mathbf{d}$ The safety hazards posed by flammable gas and residual nano-cluster liquid lithium of the lithiated anode at high temperatures, which are ready to react with the cathode (or solid-state electrolyte, SSE)-released oxygen and/or liquid electrolyte to trigger thermal runaway; the lithium melting point of $180^{\circ} \mathrm{C}$ is marked.

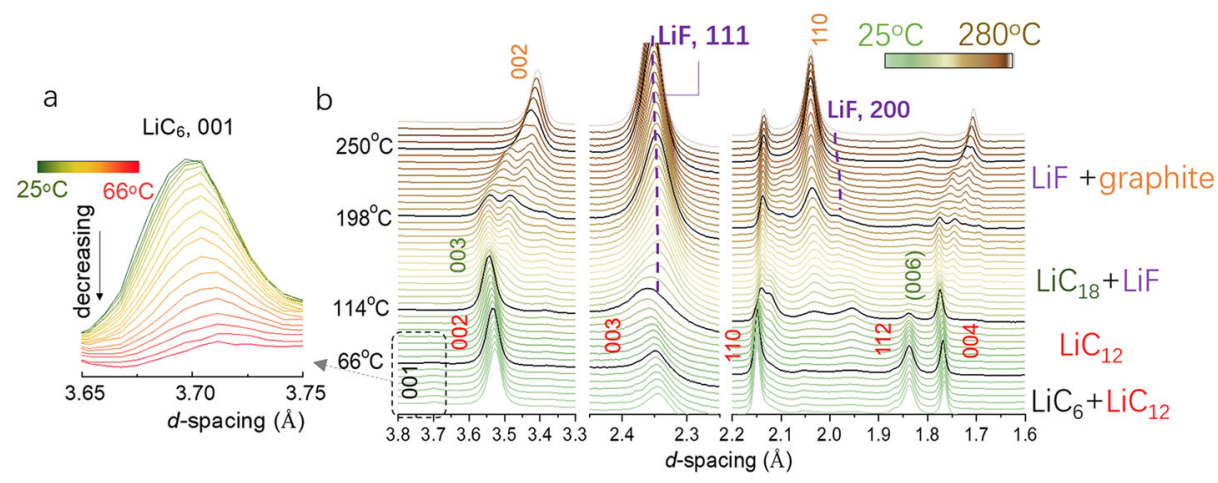

C

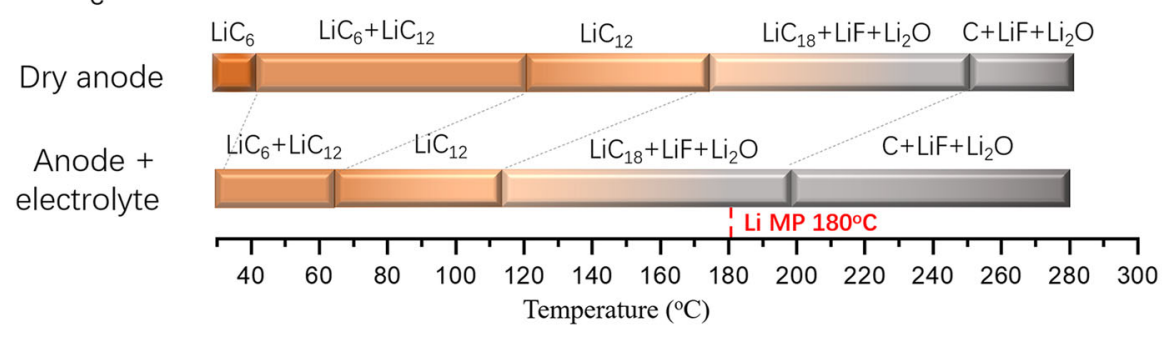

Fig. 6 The structural evolution of lithiated graphite with the electrolyte during heating. a The HEXRD plots of LiC ${ }_{6}$ (001) Bragg reflection evolution from 25 to $66^{\circ} \mathrm{C}$. $\mathbf{b}$ The HEXRD plots of lithiated graphite anode with electrolyte from 25 to $280{ }^{\circ} \mathrm{C}$ with $2{ }^{\circ} \mathrm{C} /$ min. The $2 \theta$ value has been converted into $d$ spacing following Bragg's rule. c The comparison of the phase evolution of the lithiated graphite anode with and without the presence of electrolyte. The lithium melting point (MP) $180^{\circ} \mathrm{C}$ is also described in the figure.

Supplementary Fig. 18. The disappearance of $\mathrm{LiC}_{18}(003)$ started at $198^{\circ} \mathrm{C}$ in comparison with $250^{\circ} \mathrm{C}$ for the dry lithiated graphite anode. With that, we can summarize the phase evolution pathway of the lithiated graphite anode during the heating process with and without electrolyte, as in Fig. $6 \mathrm{c}$. All phase transformations occurred at a lower temperature with an $\sim 60^{\circ} \mathrm{C}$ decrease compared to the dry lithiated graphite, implying a faster lithium leaching kinetics by reacting with the electrolytes. This is well consistent with the literature reports by DSC heat generation measurements, in which the heat generation onset temperature of the lithiated graphite decreased with the presence of electrolyte (from $\sim 220^{\circ} \mathrm{C}$ with the dry lithiated graphite to $150^{\circ} \mathrm{C}$ with the electrolyte $\left.{ }^{20,53}\right)$. The accelerated decomposition of lithiated graphite with the presence of the electrolytes is because the large amount of electrolyte salt (e.g., $\mathrm{LiPF}_{6}$ ) that can be decomposed into highly reactive products, such as $\mathrm{PF}_{5}$ (gas), $\mathrm{OPF}_{3}$, and $\mathrm{HF}$ during heating ${ }^{75}$, and electrolyte solvents (e.g., EC) that can be reduced at high temperatures ${ }^{76}$, both of which can react simultaneously with the metastable decomposition products in the SEI layer or leached lithium, therefore, lower the onset reaction 
temperature. In addition, the hidden formation of highly reactive lithium revealed here can explain the reaction mechanisms that are behind various thermal characterizations, such as DSC and ARC. For example, the thermal runaway of LIB with nonflammable electrolyte revealed by Hou et al. ${ }^{21}$. might not be triggered by the reactions between nonflammable electrolyte and $\mathrm{LiC}_{6}$, but more accurately between electrolytes and the residual liquid lithium on graphite surface; and the thermal runaway of LIBs without internal short circuit presented by Liu et al. ${ }^{20}$, should be actually attributed to the reaction between delithiatedcathode-released oxygen and liquid lithium at $231{ }^{\circ} \mathrm{C}$, rather than the $\mathrm{LiC}_{6}$. To effectively mitigate their reactions, one might focus on rational surface coating on graphite to prevent their physical contact. As a result, our present findings will stimulate more rational designs for safe LIBs.

Furthermore, it is interesting to notice the remarkable disparity in the thermal stability between the chemically prepared $\mathrm{LiC}_{6}$ (refs. ${ }^{17,22,23}$ ) and electrochemically activated $\mathrm{LiC}_{6}$ from batteries. The major difference between those two $\mathrm{LiC}_{6}$ lies in the SEI surface layer. Without the SEI, the chemically processed $\mathrm{LiC}_{6}$ is thermodynamically stable even up to $350^{\circ} \mathrm{C}$ (refs. ${ }^{17,22,23}$ ). In contrast, the $\mathrm{LiC}_{6}$ with the SEI layer decomposes immediately after the SEI breakdown starting at $40^{\circ} \mathrm{C}$. This, on one hand, calls for more attention to constructing a robust SEI to preserve the lithium in the graphite anode. On the other hand, it shows a bright future for our battery community, as the safety concerns about $\mathrm{LiC}_{6}$ can be thermodynamically alleviated like chemically prepared $\mathrm{LiC}_{6}$. Strategies for tuning the lithium reaction kinetics, such as surface coating or doping, should be taken into consideration.

In summary, with multiple in situ synchrotron X-ray characterizations, the phase evolution pattern, gas release pathway, and safety hazards of residual liquid nano-cluster lithium during the thermal degradation of the lithiated graphite anode were comprehensively illustrated. The above understanding and underlying mechanism first emphasized the role of the SEI in anode thermal stability protection. In order to prevent the lithium leaching and further reaction, a robust SEI is urgently needed. The second highlight uncovered here is the source of the flammable gas, such as $\mathrm{H}_{2}$. We showed that the initial $\mathrm{H}_{2}$ release is triggered by the SEI decomposition and the Li reaction with SEIrated ingredients; then, after $170{ }^{\circ} \mathrm{C}$, the reaction between lithium and PVDF produced more $\mathrm{H}_{2}$. A binder selection should be carefully evaluated in the future to reduce the flammable gas hazard. Last but not least, the first-time identified residual lithium on the graphite anode surface is of great importance for battery safety. Further studies on kinetically tuning of its nucleation process and mitigation technologies, such as surface coating and structural design, are highly recommended in order to control its reactivity. Our findings will stimulate extensive efforts to enable safe energy storage systems with rational design.

\footnotetext{
Methods

The lithiated graphite anode was collected from a commercially available 24 Ah vehicleuse pouch LIB. The cathode active material is $\mathrm{LiNi}_{1 / 3} \mathrm{Mn}_{1 / 3} \mathrm{Co}_{1 / 3} \mathrm{O}_{2}$, the anode composition is graphite ( $95 \mathrm{wt} . \%$ ), PVDF ( $2 \mathrm{wt} . \%$ ), and carbon black ( $3 \mathrm{wt} . \%$ ), the separator is polyethylene. The battery was charged to $4.2 \mathrm{~V}$ under constant current (1/3 C)constant voltage $(4.2 \mathrm{~V}, 1 / 20 \mathrm{C}$ cutoff current) after being charged for two cycles, then the pouch cell was carefully disassembled inside a glovebox. The lithiated graphite electrode was rinsed with dimethyl carbonate solvent followed by drying under vacuum overnight, then the lithiated graphite powder was carefully scratched from the electrode and ready for characterizations. More details about battery specifications and cycling performance are shown in the Supplementary Information.

Supplemental characterization procedures, such as in situ high-energy XRD during heating with mass spectrometry, DSC test with oxygen induction, SEM post-analysis, and in situ PDF measurement and analysis, are detailed in the Supplementary Information.
}

\section{Data availability}

The data that support the findings of this study are available from the corresponding authors G.-L.X., M.O., and K.A. upon reasonable request.

Received: 28 February 2021; Accepted: 10 June 2021; Published online: 09 July 2021

\section{References}

1. Feng, X. N. et al. Thermal runaway mechanism of lithium ion battery for electric vehicles: a review. Energy Storage Mater. 10, 246-267 (2018).

2. $\mathrm{Xu}, \mathrm{G}$. L. et al. Challenges and strategies to advance high-energy nickel-rich layered lithium transition metal oxide cathodes for harsh operation. $A d v$. Funct. Mater. 30, 2004748 (2020).

3. Liu, K., Liu, Y., Lin, D., Pei, A. \& Cui, Y. Materials for lithium-ion battery safety. Sci. Adv. 4, eaas9820 (2018).

4. Bak, S. M. et al. Structural changes and thermal stability of charged $\mathrm{LiNi}_{\mathrm{x}} \mathrm{Mn}_{\mathrm{y}} \mathrm{Co}_{\mathrm{z}} \mathrm{O}_{2}$ cathode materials studied by combined in situ time-resolved XRD and mass spectroscopy. ACS Appl. Mater. Interfaces 6, 22594-22601 (2014).

5. Liu, X. et al. Probing the thermal-driven structural and chemical degradation of Ni-rich layered cathodes by Co/Mn exchange. J. Am. Chem. Soc. 142, 19745-19753 (2020).

6. Noh, H.-J., Youn, S., Yoon, C. S. \& Sun, Y.-K. Comparison of the structural and electrochemical properties of layered $\mathrm{Li}\left[\mathrm{Ni}_{\mathrm{x}} \mathrm{Co}_{\mathrm{y}} \mathrm{Mn}_{\mathrm{z}}\right] \mathrm{O}_{2}(\mathrm{x}=1 / 3,0.5,0.6$, $0.7,0.8$ and 0.85 ) cathode material for lithium-ion batteries. J. Power Sources 233, 121-130 (2013).

7. $\mathrm{Xu}, \mathrm{G}$. L. et al. Building ultraconformal protective layers on both secondary and primary particles of layered lithium transition metal oxide cathodes. Nat. Energy 4, 484-494 (2019).

8. Zhang, J.-N. et al. Trace doping of multiple elements enables stable battery cycling of $\mathrm{LiCoO}_{2}$ at 4.6 V. Nat. Energy 4, 594-603 (2019).

9. Sun, Y. K. et al. High-energy cathode material for long-life and safe lithium batteries. Nat. Mater. 8, 320-324 (2009).

10. Li, Y., Lu, Y., Adelhelm, P., Titirici, M. M. \& Hu, Y. S. Intercalation chemistry of graphite: alkali metal ions and beyond. Chem. Soc. Rev. 48, 4655-4687 (2019).

11. Etacheri, V., Marom, R., Elazari, R., Salitra, G. \& Aurbach, D. Challenges in the development of advanced Li-ion batteries: a review. Energy Environ. Sci. 4, 3243-3262 (2011).

12. Yoshino, A. The birth of the lithium-ion battery. Angew. Chem. Int. Ed. Engl. 51, 5798-5800 (2012)

13. Kamat, P. V. Lithium-ion batteries and beyond: celebrating the 2019 Nobel Prize in chemistry - a virtual issue. Acs Energy Lett. 4, 2757-2759 (2019).

14. Chen, Z. et al. Multi-scale study of thermal stability of lithiated graphite. Energy Environ. Sci. 4, 4023-4030 (2011).

15. Heiskanen, S. K., Kim, J. \& Lucht, B. L. Generation and evolution of the solid electrolyte interphase of lithium-ion batteries. Joule 3, 2322-2333 (2019).

16. Metzger, M., Strehle, B., Solchenbach, S. \& Gasteiger, H. A. Origin of $\mathrm{H}_{2}$ evolution in LIBs: $\mathrm{H}_{2} \mathrm{O}$ reduction vs. electrolyte oxidation. J. Electrochem. Soc. 163, A798-A809 (2016).

17. Drüe, M. et al. Thermodynamic stability of $\mathrm{Li}_{2} \mathrm{C}_{2}$ and $\mathrm{LiC}_{6}$. J. Alloy Compd. 575, 403-407 (2013).

18. Pasquier, A. D. et al. Differential scanning calorimetry study of the reactivity of carbon anodes in plastic Li-ion batteries. J. Electrochem. Soc. 145, 472-477 (2019).

19. Haik, O. et al. On the thermal behavior of lithium intercalated graphites. J. Electrochem. Soc. 158, A913-A923 (2011).

20. Liu, X. et al. Thermal runaway of lithium-ion batteries without internal short circuit. Joule 2, 2047-2064 (2018).

21. Hou, J. et al. Thermal runaway of Lithium-ion batteries employing LiN $\left(\mathrm{SO}_{2} \mathrm{~F}\right)_{2}$-based concentrated electrolytes. Nat. Commun. 11, 5100 (2020).

22. Pande, V. \& Viswanathan, V. Robust high-fidelity DFT study of the lithiumgraphite phase diagram. Phys. Rev. Mater. 2, 125401 (2018).

23. Avdeev, V. V., Savchenkova, A. P., Monyakina, L. A., Nikolskaya, I. V. \& Khvostov, A. V. Intercalation reactions and carbide formation in graphitelithium system. J. Phys. Chem. Solids 57, 947-949 (1996).

24. Andersson, A. M., Edstrom, K. \& Thomas, J. O. Characterisation of the ambient and elevated temperature performance of a graphite electrode. $J$. Power Sources 81, 8-12 (1999).

25. Jiang, J. W. \& Dahn, J. R. Effects of solvents and salts on the thermal stability of $\mathrm{LiC}_{6}$. Electrochim. Acta 49, 4599-4604 (2004).

26. Oka, H. et al. Changes in the stage structure of Li-intercalated graphite electrode at elevated temperatures. J. Power Sources 482, 228926 (2021).

27. Winter, M. The solid electrolyte interphase -the most important and the least understood solid electrolyte in rechargeable Li batteries. Z. Phys. Chem. 223, 1395-1406 (2009). 
28. Son, K. et al. Thermal and chemical characterization of the solid-electrolyte interphase in Li-ion batteries using a novel separator sampling method. $J$. Power Sources 440, 227083 (2019).

29. Galushkin, N. E., Yazvinskaya, N. N. \& Galushkin, D. N. Mechanism of gases generation during lithium-ion batteries cycling. J. Electrochem. Soc. 166, A897-A908 (2019).

30. Li, W. F., Wang, H. W., Zhang, Y. J. \& Ouyang, M. G. Flammability characteristics of the battery vent gas: a case of NCA and LFP lithium-ion batteries during external heating abuse. J. Energy Storage 24, 100775 (2019).

31. Golubkov, A. W. et al. Thermal-runaway experiments on consumer Li-ion batteries with metal-oxide and olivin-type cathodes. Rsc. Adv. 4, 3633-3642 (2014).

32. Baird, A. R., Archibald, E. J., Marr, K. C. \& Ezekoye, O. A. Explosion hazards from lithium-ion battery vent gas. J. Power Sources 446, 227257 (2020).

33. Bernhard, R., Meini, S. \& Gasteiger, H. A. On-line electrochemical mass spectrometry investigations on the gassing behavior of $\mathrm{Li}_{4} \mathrm{Ti}_{5} \mathrm{O}_{12}$ electrodes and its origins. J. Electrochem. Soc. 161, A497-A505 (2014).

34. Wu, K. et al. Investigation on gas generation of $\mathrm{Li}_{4} \mathrm{Ti}_{5} \mathrm{O}_{12} / \mathrm{LiNi}_{1 / 3} \mathrm{Co}_{1 / 3} \mathrm{Mn}_{1 /}$ ${ }_{3} \mathrm{O}_{2}$ cells at elevated temperature. J. Power Sources 237, 285-290 (2013).

35. Hashimoto, M. et al. Mechanism of gas generation in lithium ion batteries by overdischarge. Ecs Trans. 69, 17-22 (2015).

36. Jin, $\mathrm{Y}$. et al. Detection of micro-scale Li dendrite via $\mathrm{H}_{2}$ gas capture for early safety warning. Joule 4, 1714-1729 (2020).

37. Wu, X. K. et al. Safety issues in lithium ion batteries: materials and cell design. Front. Energy Res. 7, 65 (2019).

38. Li, N. \& Su, D. In-situ structural characterizations of electrochemical intercalation of graphite compounds. Carbon Energy 1, 200-218 (2019).

39. Peled, E. \& Menkin, S. Review-SEI: past, present and future. J. Electrochem. Soc. 164, A1703-A1719 (2017)

40. Chattopadhyay, S. et al. In situ X-ray study of the solid electrolyte interphase (SEI) formation on graphene as a model Li-ion battery anode. Chem. Mater. 24, 3038-3043 (2012).

41. Huang, W. et al. Dynamic structure and chemistry of the silicon solidelectrolyte interphase visualized by cryogenic electron microscopy. Matter $\mathbf{1}$, 1232-1245 (2019).

42. Huang, W. et al. Evolution of the solid-electrolyte interphase on carbonaceous anodes visualized by atomic-resolution cryogenic electron microscopy. Nano Lett. 19, 5140-5148 (2019).

43. Nanda, J. et al. Unraveling the nanoscale heterogeneity of solid electrolyte interphase using tip-enhanced raman spectroscopy. Joule 3, 2001-2019 (2019).

44. Parimalam, B. S., MacIntosh, A. D., Kadam, R. \& Lucht, B. L. Decomposition reactions of anode solid electrolyte interphase (SEI) components with $\mathrm{LiPF}_{6} . J$. Phys. Chem. C 121, 22733-22738 (2017).

45. Yoon, T., Millen, M. S., Parimalam, B. S. \& Lucht, B. L. Thermal decomposition of the solid electrolyte interphase (SEI) on silicon electrodes for lithium ion batteries. Chem. Mater. 29, 3237-3245 (2017).

46. Huang, S. Q., Cheong, L. Z., Wang, D. Y. \& Shen, C. Thermal stability of solid electrolyte interphase of lithium-ion batteries. Appl. Surf. Sci. 454, 61-67 (2018).

47. Chan, C. K., Ruffo, R., Hong, S. S. \& Cui, Y. Surface chemistry and morphology of the solid electrolyte interphase on silicon nanowire lithium-ion battery anodes. J. Power Sources 189, 1132-1140 (2009).

48. Owejan, J. E., Owejan, J. P., DeCaluwe, S. C. \& Dura, J. A. Solid electrolyte interphase in Li-ion batteries: evolving structures measured in situ by neutron reflectometry. Chem. Mater. 24, 2133-2140 (2012).

49. Michan, A. L., Leskes, M. \& Grey, C. P. Voltage dependent solid electrolyte interphase formation in silicon electrodes: monitoring the formation of organic decomposition products. Chem. Mater. 28, 385-398 (2015)

50. Gachot, G. et al. Deciphering the multi-step degradation mechanisms of carbonate-based electrolyte in Li batteries. J. Power Sources 178, 409-421 (2008).

51. Tavassol, H., Buthker, J. W., Ferguson, G. A., Curtiss, L. A. \& Gewirth, A. A. Solvent oligomerization during SEI formation on model systems for Li-ion battery anodes. J. Electrochem. Soc. 159, A730-A738 (2012).

52. Rao, Y. \& Blanton, T. N. Polymer nanocomposites with a low thermal expansion coefficient. Macromolecules 41, 935-941 (2008).

53. Roth, E. P., Doughty, D. H. \& Franklin, J. DSC investigation of exothermic reactions occurring at elevated temperatures in lithium-ion anodes containing PVDF-based binders. J. Power Sources 134, 222-234 (2004).

54. Ren, D. S. et al. Model-based thermal runaway prediction of lithium-ion batteries from kinetics analysis of cell components. Appl. Energy 228, 633-644 (2018).

55. Tripathi, A. M., Su, W. N. \& Hwang, B. J. In situ analytical techniques for battery interface analysis. Chem. Soc. Rev. 47, 736-851 (2018).

56. Jung, R., Metzger, M., Maglia, F., Stinner, C. \& Gasteiger, H. A. Oxygen release and its effect on the cycling stability of $\mathrm{LiNi}_{\mathrm{x}} \mathrm{Mn}_{\mathrm{y}} \mathrm{Co}_{\mathrm{z}} \mathrm{O}_{2}$ (NMC) cathode materials for Li-ion batteries. J. Electrochem. Soc. 164, A1361-A1377 (2017).
57. Lammer, M., Konigseder, A. \& Hacker, V. Characterisation of heat and gas emissions in thermally induced battery failure on commercially available 18650 Li-ion cells. ECS Trans. 80, 135-143 (2017).

58. Roth, E. P. \& Orendorff, C. J. How electrolytes influence battery safety. Interface Mag. 21, 45-49 (2012).

59. Strehle, B., Solchenbach, S., Metzger, M., Schwenke, K. U. \& Gasteiger, H. A. The effect of $\mathrm{CO}_{2}$ on alkyl carbonate trans-esterification during formation of graphite electrodes in Li-ion batteries. J. Electrochem. Soc. 164, A2513-A2526 (2017).

60. Choukourov, A. et al. Vacuum thermal degradation of poly(ethylene oxide). J. Phys. Chem. B 113, 2984-2989 (2009).

61. Royer, S. J., Ferron, S., Wilson, S. T. \& Karl, D. M. Production of methane and ethylene from plastic in the environment. PLoS ONE 13, e0200574 (2018).

62. $\mathrm{Xu}, \mathrm{K}$. et al. Syntheses and characterization of lithium alkyl mono- and dicarbonates as components of surface films in Li-ion batteries. J. Phys. Chem. B 110, 7708-7719 (2006).

63. Kriston, A., Adanouj, I., Ruiz, V. \& Pfrang, A. Quantification and simulation of thermal decomposition reactions of Li-ion battery materials by simultaneous thermal analysis coupled with gas analysis. J. Power Sources $\mathbf{4 3 5}$, 226774 (2019)

64. Tsuneto, A., Kudo, A. \& Sakata, T. Lithium-mediated electrochemical reduction of high-pressure $\mathrm{N}_{2}$ to $\mathrm{NH}_{3}$. J. Electroanal. Chem. 367, 183-188 (1994).

65. Chen, R. S. et al. The thermal stability of lithium solid electrolytes with metallic lithium. Joule 4, 812-821 (2020).

66. Bernhard, R., Metzger, M. \& Gasteiger, H. A. Gas evolution at graphite anodes depending on electrolyte water content and SEI quality studied by on-line electrochemical mass spectrometry. J. Electrochem. Soc. 162, A1984-A1989 (2015).

67. Feng, X. N. et al. Investigating the thermal runaway mechanisms of lithiumion batteries based on thermal analysis database. Appl. Energy 246, 53-64 (2019).

68. Yuan, L., Dubaniewicz, T., Zlochower, I., Thomas, R. \& Rayyan, N. Experimental study on thermal runaway and vented gases of lithium-ion cells Process Saf. Environ. Prot. 144, 186-192 (2020).

69. Xiaowei, L., Jean-Charles, R. \& Suyuan, Y. Effect of temperature on graphite oxidation behavior. Nucl. Eng. Des. 227, 273-280 (2004).

70. Liu, J. et al. Quantitative analysis of the morphology of $\{101\}$ and $\{001\}$ faceted anatase $\mathrm{TiO}_{2}$ nanocrystals and its implication on photocatalytic activity. Chem. Mater. 29, 5591-5604 (2017).

71. Wang, X. et al. Glassy Li metal anode for high-performance rechargeable Li batteries. Nat. Mater. 19, 1339-1345 (2020).

72. Baran, V., Dolotko, O., Muhlbauer, M. J., Senyshyn, A. \& Ehrenberg, H. Thermal structural behavior of electrodes in Li-ion battery studied in operando. J. Electrochem. Soc. 165, A1975-A1982 (2018).

73. Chen, M., Hung, L., Huang, C., Xia, J. \& Carter, E. The melting point of lithium: an orbital-free first-principles molecular dynamics study. Mol. Phys. 111, 3448-3456 (2013).

74. Salmon, P., Petri, I., Jong, P., Verkerk, H. \& Howells, W. Structure of liquid lithium. J. Phys. Condens. Matter 16, 195-222 (2004).

75. Choi, N. S., Profatilova, I. A., Kim, S. S. \& Song, E. H. Thermal reactions of lithiated graphite anode in $\mathrm{LiPF}_{6}$-based electrolyte. Thermochim. Acta 480, 10-14 (2008).

76. Hou, J. et al. Unlocking the self-supported thermal runaway of high-energy lithium-ion batteries. Energy Storage Mater. 39, 395-402 (2021).

\section{Acknowledgements}

Research at Argonne National Laboratory was funded by the US Department of Energy (DOE) Vehicle Technologies Office. Support from Tien Duong of DOE's Vehicle Technologies Office is gratefully acknowledged. Use of the Advanced Photon Source was supported by the US Department of Energy, Office of Science and Office of Basic Energy Sciences, under Contract No. DEAC02-06CH11357. The Ministry of Science and Technology of China is acknowledged under Grant No. 2019YFE0100200. X.L., G.-L.X., M.O., and K.A. acknowledge the support of the U.S. China Clean Energy Research Center (CERC-CVC2)

\section{Author contributions}

X.L. and G.-L.X. conceived the idea; X.L. performed in situ heating HEXRD with gas analysis and processed the data; L.Y. and X.L. carried out the in situ heating PDF and analyzed the data; D.R. prepared the lithiated graphite anode and conducted the DSC measurement; L.W., Y.R., W.X., S.L., H.W., X.H., and Z.C. helped with data analysis. X.L and G.-L.X. prepared the manuscript; G.-L.X., M.O., and K.A. managed the project; and all authors contributed to discussions and paper revisions.

\section{Competing interests}

The authors declare no competing interests. 


\section{Additional information}

Supplementary information The online version contains supplementary material available at https://doi.org/10.1038/s41467-021-24404-1.

Correspondence and requests for materials should be addressed to G.-L.X., M.O. or K.A.

Peer review information Nature Communications thanks Chunguang Chen, Qiang Fu and the other, anonymous, reviewer(s) for their contribution to the peer review of this work. Peer reviewer reports are available.

Reprints and permission information is available at http://www.nature.com/reprints

Publisher's note Springer Nature remains neutral with regard to jurisdictional claims in published maps and institutional affiliations. (c) (P) Open Access This article is licensed under a Creative Commons Attribution 4.0 International License, which permits use, sharing, adaptation, distribution and reproduction in any medium or format, as long as you give appropriate credit to the original author(s) and the source, provide a link to the Creative Commons license, and indicate if changes were made. The images or other third party material in this article are included in the article's Creative Commons license, unless indicated otherwise in a credit line to the material. If material is not included in the article's Creative Commons license and your intended use is not permitted by statutory regulation or exceeds the permitted use, you will need to obtain permission directly from the copyright holder. To view a copy of this license, visit http://creativecommons.org/ licenses/by/4.0/.

This is a U.S. Government work and not under copyright protection in the US; foreign copyright protection may apply 2021 